\title{
The teaching of biochemistry and microbiology through practical classes in an interdisciplinary approach
}

\section{O ensino de bioquímica e microbiologia por meio de aulas práticas em uma abordagem interdisciplinar}

Mario Davi Martins de Lacerda ${ }^{1}$, Álvaro Júlio Pereira² ${ }^{2}$ José Fernando Mourão Cavalcante ${ }^{2^{*}}$ ${ }^{1}$ Instituto Federal do Ceará, Campus de Iguatu-CE, ${ }^{2}$ Departamento de Ciências Biológicas, Universidade Estadual do Ceará, Brasil.

*e-mail: jose.fernando@uece.br

\begin{abstract}
Active learning methodologies allow students to participate in a teaching and learning process that values critical and reflective training, giving meaning to the contemporary context. This work aimed to evaluate the impact of teaching and learning concepts of biochemistry and microbiology, through practical activities, in the teaching of Biology. The research was based on active methodologies and the actions were divided into two stages: 1) elaboration and application of practical activities; 2) evaluation of practical classes and application of a specific questionnaire. The practical classes were evaluated by the students through direct questions using the structured hedonic scale of five points. Brainstorming technique was applied to concepts that students had before and after the experiments. It is concluded that teaching biochemistry and microbiology, through practical classes, with an interdisciplinary

approach had an important impact on student learning.
\end{abstract}

Keywords: Biology teaching; Energy metabolism; Practical classes; Interdisciplinarity.

\section{Resumo}

As metodologias ativas de aprendizagem permitem que os alunos participem de um processo de ensino e aprendizagem que valorize a formação crítica e reflexiva, dando significado ao contexto contemporâneo. Este trabalho teve como objetivo avaliar o impacto do ensino e aprendizado de conceitos de bioquímica e microbiologia, por meio de atividades práticas, no ensino de Biologia. A pesquisa foi fundamentada em metodologias ativas e as ações foram divididas em duas etapas: 1) elaboração e aplicação de atividades práticas; 2) avaliação de aulas práticas e aplicação de questionário específico. As aulas práticas foram avaliadas pelos alunos por meio de perguntas diretas usando a escala hedônica estruturada de cinco pontos. Aplicou-se a técnica de Brainstorming sobre conceitos que os alunos tinham antes e depois dos experimentos. Concluiu-se que o ensino de bioquímica e microbiologia, por meio de aulas práticas, com uma abordagem interdisciplinar, teve importante impacto no aprendizado dos alunos.

Palavras-chave: Ensino de Biologia; Metabolismo energético; Aulas práticas; Interdisciplinaridade. 


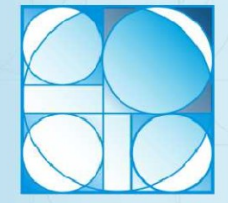

REB na escola
Journal of Biochemistry Education

Revista de Ensino de Bioquímica

Revista de Enseñanza de Bioquímica

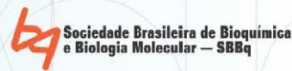

V. 20, N.1 / 2020

Submitted in: 4 jun 2020 Published in: 10 ago 2020

ISSN: 2318-8790

ISSN (until 2012): 1677-2318

\section{Ficha da atividade desenvolvida}

\begin{tabular}{|c|c|}
\hline Título & $\begin{array}{l}\text { O ensino de bioquímica e microbiologia por meio de aulas práticas em } \\
\text { uma abordagem interdisciplinar. }\end{array}$ \\
\hline o-alvo & $\begin{array}{l}\text { Professores do ensino médio e superior, bem como alunos de cursos de } \\
\text { licenciatura, especialmente da área de ciências (biológicas, naturais e } \\
\text { químicas). }\end{array}$ \\
\hline $\begin{array}{l}\text { linas } \\
\text { nadas }\end{array}$ & $\begin{array}{l}\text { No ensino superior: Bioquímica, Microbiologia geral, Fisiologia vegetal, } \\
\text { Métodos instrumentais para o ensino de Biologia/Química/Bioquímica. } \\
\text { No ensino médio: Biologia, Química e Física. No ensino fundamental: } \\
\text { Ciências. }\end{array}$ \\
\hline onais & $\begin{array}{l}\text { Avaliar o impacto do aprendizado de conceitos de Bioquímica e } \\
\text { Microbiologia, por meio de atividades práticas, no ensino de Biologia, } \\
\text { para o entendimento de temas de alta complexidade e abstração. }\end{array}$ \\
\hline $\begin{array}{l}\text { Jus } \\
\text { do }\end{array}$ & $\begin{array}{l}\text { O aprendizado de conceitos de Bioquímica, como fermentação, } \\
\text { fotossíntese e metabolismo energético. Estes conceitos são } \\
\text { considerados de difícil compreensão no ensino médio e no ensino } \\
\text { superior, o que justifica sua abordagem por meio de metodologias com } \\
\text { maior envolvimento discente e com estímulo à criatividade e à autonomia } \\
\text { do estudante para lidar com diferentes situações-problema. }\end{array}$ \\
\hline or & $\begin{array}{l}\text { Aula teórica com os conceitos básicos de fermentação, de fotossíntese e } \\
\text { de respiração celular, incluindo um breve histórico sobre personagens } \\
\text { que descobriram estes fenômenos, com discussão de cada conteúdo. } \\
\text { Formulação de perguntas pelos alunos. Divisão em grupos para a } \\
\text { elaboração das propostas de experimentos e início da atividade } \\
\text { experimental, mas também das potencialidades que a sala de aula } \\
\text { invertida apresenta para outros temas de alta complexidade. Discussão } \\
\text { dos resultados obtidos. }\end{array}$ \\
\hline $\begin{array}{l}\text { Du } \\
\text { est }\end{array}$ & $\begin{array}{l}\text { Sete dias de aula, sendo: 1) Abertura das atividades práticas; 2)Aulas } \\
\text { práticas: breve histórico sobre fermentação, fotossíntese e respiração } \\
\text { celular, em dias diferentes; 3) Formulação de perguntas pelos alunos; 4) } \\
\text { Formação de grupos de alunos para elaboração das propostas de } \\
\text { experimentos e início da atividade experimental; 5) Discussão dos } \\
\text { resultados obtidos nos experimentos; 6) Aula expositiva sobre a vivência } \\
\text { dos alunos e os conteúdos trabalhados. }\end{array}$ \\
\hline $\begin{array}{l}\text { Materiais } \\
\text { usados }\end{array}$ & $\begin{array}{l}\text { Textos, leite pasteurizado ou esterilizado, pote de vidro, colher de aço } \\
\text { inox, iogurte natural, estufa bacteriológica, geladeira comum; folhas de } \\
\text { plantas verdes, lâmpada de } 100 \mathrm{~W} \text {, pipeta graduada, relógio ou } \\
\text { cronômetro (celular), tubo de látex, bécker; fermento biológico, garrafas } \\
\text { ou tubos de vidro, balões ou bexigas, banho-maria, glicose, etanol, } \\
\text { piruvato-malato, vinagre comum (inibidor), hidróxido de bário. }\end{array}$ \\
\hline in & ogle.com/file/d/16PK8ksZJAAkfwyGq1zkF6kmg1-jnA1vY/ \\
\hline
\end{tabular}




\section{Journal of Biochemistry Education}

Revista de Ensino de Bioquímica

Revista de Enseñanza de Bioquímica

REB na escola
V. 20, N.1 / 2020

Submitted in: 4 jun 2020 Published in: 10 ago 2020

ISSN: 2318-8790

ISSN (until 2012): 1677-2318

\section{Introdução}

O potencial educacional do aprendizado de conceitos de Bioquímica, como a fermentação, fotossíntese e metabolismo energético, por meio de atividades práticas, está relacionado ao exercício da metodologia científica, à vivência dos alunos do Ensino Básico e ao estímulo à criatividade e à autonomia para lidar com diferentes situações-problema [1].

Muitas vezes o professor de Ciências ensina sem saber como se dá o processo de construção dos conceitos que estão nos livros didáticos de Biologia. Para superar esse grande desafio, é preciso que os próprios alunos criem suas hipóteses e desenhem seus experimentos para responder aos questionamentos iniciais, semelhante ao que fazem os cientistas em seus laboratórios de pesquisa [2,3].

O modelo tradicional de ensino é ainda amplamente utilizado por muitos educadores nas escolas de ensino fundamental e médio no Brasil. Este modelo de educação trata o conhecimento como um conjunto de informações que são simplesmente repassadas dos professores para os alunos, o que nem sempre resulta em aprendizado efetivo. Os alunos fazem papel de ouvintes e, na maioria das vezes, os conhecimentos ministrados pelos professores não são realmente assimilados pelos alunos. Esses conhecimentos são apenas memorizados por um curto período de tempo e, geralmente, esquecidos em poucas semanas ou meses, comprovando a não ocorrência de um verdadeiro aprendizado [4].

Diante disso, sugiram os seguintes questionamentos: será que atividades práticas, como as aulas de laboratório, podem funcionar somente como um complemento das aulas teóricas ou como uma poderosa ferramenta no processo de aquisição de novos conhecimentos? É possível que a vivência de uma aula prática facilite a fixação dos conteúdos teóricos de Bioquímica e Microbiologia?

A construção de novos conhecimentos deve sempre partir do conhecimento prévio dos alunos, mesmo que intuitivos e derivados, levando-se em consideração que o processo de aprendizagem implica a desestruturação e consequente reformulação dos conhecimentos através do diálogo e reflexão. Alunos do ensino fundamental da rede pública, na maioria das vezes, deparam-se com metodologias que nem sempre promovem a efetiva construção de seu conhecimento [5]. 


\section{Journal of Biochemistry Education}

Revista de Ensino de Bioquímica

Revista de Enseñanza de Bioquímica

REB na escola

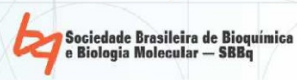

SSN: 2318-8790

ISSN (until 2012): 1677-2318

O método de investigação e problematização pode ser uma alternativa viável para o ensino de Ciências e Biologia, no sentido de propiciar uma postura ativa dos estudantes no processo de investigação e na resolução de problemas e de contribuir para uma visão integrada sobre a Ciência. [6].

A organização de experimentos em torno de problemas e hipóteses possibilita, por um lado, superar a concepção empirista a qual afirma que o conhecimento se origina unicamente a partir da observação e, por outro lado, relacionar o conteúdo a ser aprendido com os conhecimentos prévios dos alunos. Entretanto, problemas dessa natureza geralmente não se enquadram bem em disciplinas específicas, exigindo uma abordagem interdisciplinar. Isto nos leva a outra característica das experimentações construtivistas, ou seja, o envolvimento de várias disciplinas ao mesmo tempo, sendo possível demonstrar para os alunos que todas elas estão interligadas [5].

O Brasil tem alcançado, nas últimas décadas, um grande e consistente aumento na formação de mestres e doutores e na produção de conhecimento científico. Entretanto, este fato contrasta dramaticamente com o baixo desempenho dos nossos alunos da Educação Básica, especialmente nas áreas de Ciências, como mostram os resultados do Programme for International Student Assessment- PISA 2018, no qual o Brasil ocupa a posição 63 dentre os 70 países participantes do último levantamento [7].

Desta forma, este triste cenário sugere a necessidade urgente de se buscar novos mecanismos de transferências do conhecimento científico pelos professores para dentro das salas de aula nas escolas públicas do ensino médio.

As metodologias ativas de aprendizagem são aquelas em que o aluno interage com o assunto em estudo - ouvindo, falando, perguntando, discutindo, fazendo e ensinando - sendo estimulado a construir o conhecimento ao invés de recebê-lo de forma passiva do professor. Em um ambiente de aprendizagem ativa, o professor atua como orientador, supervisor, facilitador do processo de aprendizagem, e não apenas como fonte única de informação e conhecimento [8].

No Brasil, o ensino médio consiste na última etapa da educação básica, tem duração média de três anos e antecede o ingresso do aluno ao ensino superior. O objetivo dessa etapa de ensino é propiciar uma formação voltada para o mercado de trabalho, aprimorar os conhecimentos do cidadão já adquiridos nas etapas anteriores e a preparar os estudantes para os exames de acesso ao ensino superior. 


\section{Journal of Biochemistry Education}

Revista de Ensino de Bioquímica

Revista de Enseñanza de Bioquímica

REB na escola

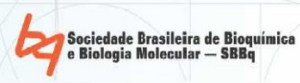

V. 20, N.1 / 2020

Submitted in: 4 jun 2020 Published in: 10 ago 2020

ISSN: 2318-8790

ISSN (until 2012): 1677-2318

O presente estudo teve como objetivo avaliar o impacto e implicações do aprendizado de conceitos de Bioquímica e Microbiologia, por meio de atividades práticas, no ensino da Biologia, em uma escola do ensino médio de Iguatu-CE. Estes conceitos estão relacionados aos principais temas da Bioquímica, como fermentação, fotossíntese e respiração celular, que foram desenvolvidos de forma investigativa por meio de atividades práticas.

\subsection{Contextualizando o ensino da bioquímica e microbiologia na biologia numa abordagem interdisciplinar}

A interdisciplinaridade é uma discussão emergente no meio educacional: uma forma de se pensar, no interior da Educação, a superação da abordagem disciplinar tradicionalmente fragmentária. Essa, frequentemente, é apontada como incapaz de atender às demandas por um ensino contextualizado. Em tese, a interdisciplinaridade é entendida como a necessidade de integrar, articular, trabalhar em conjunto [9].

Os espaços de aprendizagem configurados com base em resolução de problemas possibilitam ao aluno ter percepções múltiplas da realidade, as quais contribuem para a sua capacidade de superação de obstáculos e estimulam a atividade cognitiva. Ocorre, assim, a construção de conhecimentos, tendo como ponto de partida as abstrações que proporcionam o desenvolvimento cognitivo criativo, sob a premissa de que não se aprende copiando ou reproduzindo a realidade, e sim a partir do seu entendimento [10].

A Bioquímica é um campo de conhecimento da Biologia, que faz amplo uso da abstração e imaginação para descrever os fenômenos que ocorrem em nível molecular, sendo, no entanto, difícil descrever seus fenômenos apenas com instrumentos, como quadro negro e outros presentes de forma mais acessível no ambiente escolar [11].

Mesmo existindo para o ensino da Bioquímica, dois modelos, o teórico e o prático, quando tratados em momentos diferentes, trazem um distanciamento temporal entre prática e teoria. Dessa forma, é fundamental a adoção de um modelo de ensino teórico-prático, que é mais produtivo, mais atrativo para o aluno, proporcionando-Ihe a participação de forma ativa no processo de aprendizagem [12].

Assim, não há dúvidas do quanto as aulas práticas, com abordagem investigativa, podem melhorar a aprendizagem, sendo uma estratégia importante no processo de ensino-aprendizagem. No entanto, as aulas práticas não são muito comuns nas escolas da educação básica, inclusive vários autores têm se dedicado a realizar um levantamento de quais seriam os motivos de os professores não as 


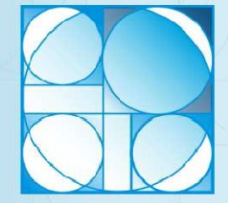

REB na escola
Journal of Biochemistry Education

Revista de Ensino de Bioquímica

Revista de Enseñanza de Bioquímica

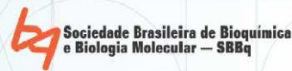

V. 20, N.1 / 2020

Submitted in: 4 jun 2020 Published in: 10 ago 2020

ISSN: 2318-8790

ISSN (until 2012): 1677-2318

utilizarem em seu trabalho. Os motivos apontados foram a falta de laboratórios, a escassez de recursos, as turmas numerosas e a falta de conhecimento sobre o assunto pelos professores [13].

A Microbiologia é o ramo e especialidade da Biologia que estuda os pequenos seres vivos, que, salvo algumas exceções, não são vistos a olho nu. É uma outra área do saber, na qual se percebe grandes desafios, no que diz respeito ao seu ensino e aprendizagem. Ela também estuda a interação entre os microrganismos e outros seres vivos, com ênfase nos benefícios e malefícios potenciais para o ecossistema (em particular para espécie humana) e as alterações físicas e químicas no meio ambiente [14].

Entre as principais dificuldades encontradas no ensino da Microbiologia é a falta de conexão do que é ensinado em sala de aula com o cotidiano dos alunos, o que acaba tornando mais difícil a aprendizagem [15]. Portanto, é de fundamental importância que se adotem estratégias de ensino, como o uso de tecnologias e outros recursos adequados, que possam despertar no aluno o interesse pelo conhecimento dos microrganismos e sua relação com o seu cotidiano, tornando-o mais contextualizado.

É desejável que o mundo microbiano e sua aplicabilidade estejam relacionados com a nossa qualidade de vida. Esta relação não envolve somente os efeitos prejudiciais de certos microrganismos, como as doenças e a deterioração de alimentos, mas sobretudo seus efeitos benéficos, como a produção industrial de alimentos, produtos químicos e antibióticos e também no tratamento de detritos, controle de pestes e a limpeza de poluentes, dentre outros [16].

De acordo com Barbosa e Barbosa [17], há algo peculiar no ensino da Microbiologia, pois são necessárias estratégias de ensino que possam incentivar o aluno na percepção de um universo novo, ou seja, aquele dos pequenos seres visíveis somente ao microscópio. O estudante, ao apreender esses conhecimentos, através da aprendizagem significativa, poderá obter uma vivência de aprendizagem mais satisfatória, que certamente lhe proporcionará mudanças em seus hábitos e atitudes, por meio da assimilação dos conteúdos científicos.

Muitas vezes, assuntos ligados ao cotidiano e à realidade social dos alunos, tais como o relacionamento dos microrganismos com a saúde humana, podem ser abordados pelo professor de maneira interdisciplinar. Um dos pilares que sustentam o aparente consenso em torno da importância da implantação da interdisciplinaridade no ensino é a crença de que esta aproximaria os conteúdos escolares do cotidiano do aluno [9]. 


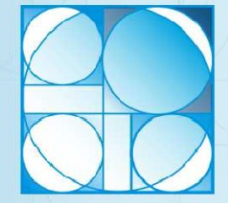

REB na escola

\section{Journal of Biochemistry Education}

Revista de Ensino de Bioquímica

Revista de Enseñanza de Bioquímica

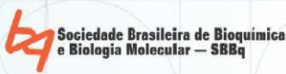

V. 20, N.1 / 2020

Submitted in: 4 jun 2020 Published in: 10 ago 2020

\section{Procedimentos metodológicos}

\subsection{Tipologia da pesquisa}

Esta pesquisa foi do tipo "quanti-qualitativa", pois apresentou dados numéricos e textuais, com o fito de compreender o fenômeno estudado. O estudo foi realizado de forma a fundamentar a pesquisa no paradigma atividades práticas/criatividade. Portanto, os resultados da presente pesquisa foram influenciados pela interação do pesquisador (professor) com os pesquisados (alunos), sendo a pesquisa investigativa da área da Educação [18].

\subsection{Local de coleta e participantes da pesquisa}

A pesquisa foi aplicada em uma Escola de Ensino Médio do Instituto Federal do Ceará (IFCE), localizada na cidade de Iguatu, Ceará. Os participantes da pesquisa foram 29 alunos do $3^{\circ}$ ano do Ensino Médio da referida instituição, sendo 23 alunos do sexo masculino e 06 do sexo feminino, na faixa etária de 16 a 19 anos de idade. A pesquisa foi realizada nos dias 18,19, 25 e 27 de junho e nos dias 02, 03 e 04 de julho de 2019.

Os experimentos foram realizados no Laboratório do IFCE- unidade de Iguatu-CE, e, após cada aula prática, foi ministrada uma aula expositiva sobre a vivência dos alunos e sobre os conteúdos trabalhados.

Foi aplicada aos alunos a técnica de Brainstorming ("chuva de ideias") sobre os conceitos que eles tinham antes e depois de cada tema abordado nos experimentos [19].

\subsection{Aspectos éticos}

A pesquisa foi realizada de acordo com as exigências éticas e científicas fundamentais, contidas na Resolução $n^{\circ}$ 466/2012, que regulamenta as pesquisas envolvendo seres humanos [20]. O projeto foi aprovado pelo Comitê de Ética da Universidade Estadual do Ceará (UECE) conforme parecer $n^{\circ} 3.465 .873$ e CAAE: 13312819.3 .0000 .5534 .

\subsection{Metodologia para a coleta de dados}

Sendo o estudo com base em metodologias ativas, a partir da intervenção pedagógica, as ações 


\section{Journal of Biochemistry Education}

Revista de Ensino de Bioquímica

Revista de Enseñanza de Bioquímica

REB na escola
V. 20, N.1 / 2020

Submitted in: 4 jun 2020 Published in: 10 ago 2020

foram divididas em duas etapas, a saber:

$1^{\text {a }}$ Etapa: Elaboração e aplicação das atividades práticas

O planejamento das atividades práticas e os materiais e procedimentos dos experimentos estão descritos nos Apêndices A e B (Materiais adicionais).

Para o desenvolvimento das atividades práticas que abordam temas de Bioquímica como a fermentação, a fotossíntese e a respiração celular, foram utilizadas os seguintes procedimentos:

- apresentação de um breve histórico das principais descobertas e os personagens envolvidos com o tema em questão. Este início serviu como motivação para o momento seguinte, no qual os alunos foram divididos em grupos (3 a 5 alunos) e formularam perguntas relacionadas ao tema (Apêndices D, E e F) (Materiais adicionais);

- depois, os grupos foram desafiados a buscar respostas para suas perguntas, por meio da experimentação, sendo estimulados a desenhar experimentos simples, que podiam fornecer resultados às perguntas;

- cada tema abordado foi desenvolvido em dois dias diferentes, o que correspondeu a seis dias de aulas. No segundo dia de cada tema, os grupos participantes apresentaram para os demais colegas a pergunta formulada pelo grupo e os resultados obtidos por meio dos experimentos que desenharam para respondê-la (Apêndices $A$ e B);

- uma aula teórica contendo os conceitos fundamentais sobre cada tema foi ministrada após a discussão dos resultados, perfazendo 7 dias/aulas.

No que concerne à fermentação, foi tratado o papel das bactérias lácticas (benéficas) no processo de fermentação lática, como na produção de iogurte e queijos [21]. Os alunos participaram ativamente, preparando iogurte e outros leites fermentados. Depois, degustaram os produtos lácteos preparados por eles mesmos.

Quanto ao tópico fotossíntese, o foco dessa aula prática foi a sua importância para os seres vivos, de onde a planta "tira seu alimento". Esta aula pôde reforçar que é a luz do Sol e não o solo que provê a energia para o crescimento vegetal [22].

No que concerne ao tópico respiração celular, foi realizada uma atividade prática em que o aluno identificou o mecanismo de respiração celular, compreendendo sua importância para o corpo humano [23].

$\mathrm{Na}$ primeira série do IFCE-Iguatu, os alunos já estudaram o metabolismo energético das 


\section{Journal of Biochemistry Education}

Revista de Ensino de Bioquímica

Revista de Enseñanza de Bioquímica

REB na escola

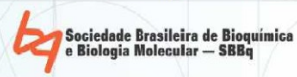

células, incluindo a fermentação lática, e, na segunda série foram ministrados os conteúdos referentes aos seres vivos, incluindo os microrganismos. As aulas expositivas foram ministradas somente pelo pesquisador/professor, já, nas atividades de laboratório, houve o auxílio do técnico de laboratório.

$2^{\text {a }}$ Etapa- Avaliação das aulas práticas e aplicação do questionário

No sétimo dia, foram avaliadas as aulas práticas pelos alunos, por meio de um questionário com perguntas diretas (APÊNDICE C), utilizando a escala hedônica estruturada de cinco pontos, variando de "Concordo totalmente a Discordo totalmente" ou "Gostei muito a Desgostei muito" [24]. Além disso, os alunos indicaram os pontos positivos e negativos dos temas abordados [1].

$\mathrm{Na}$ aplicação do questionário, foi explicado aos alunos que seria uma avaliação do processo de aprendizagem. Os alunos receberam orientações quanto à liberdade que tinham ao efetuarem as respostas. As folhas de respostas não foram numeradas nem continham identificação, garantindo, dessa forma, o anonimato dos alunos.

Todas as respostas do questionário foram compiladas, organizadas em planilhas empregando o programa Excel ${ }^{\circledR}$ e, posteriormente foram elaborados gráficos ilustrativos em formato de pizza para uma melhor visualização dos resultados.

\section{Resultados e Discussão}

No Quadro 1, apresentamos as percepções dos alunos, antes e depois da realização do experimento sobre o processo de fermentação, que envolveu a ação das bactérias ácido lácticas (benéficas), no processo de fermentação lática, que é comumente usada na produção de iogurte e queijos.

\begin{tabular}{|l|l|}
\hline \multicolumn{1}{|c|}{ ANTES do EXPERIMENTO } & \multicolumn{1}{c|}{ DEPOIS do EXPERIMENTO } \\
\hline $\begin{array}{l}\text { "eu sei que é usado em bolos, na } \\
\text { fabricação de bebidas, como por } \\
\text { exemplo, cerveja" }\end{array}$ & $\begin{array}{l}\text { (Eu agora sei que as bactérias lácticas } \\
\text { nutrição da pessoa [...] e para alimentar } \\
\text { essas bactérias é preciso alimentos } \\
\text { íntegros e integrais" }\end{array}$ \\
\hline $\begin{array}{l}\text { "É um fenômeno químico, sem a } \\
\text { presença de oxigênio, que transforma }\end{array}$ & $\begin{array}{l}\text { "Tudo que é alimento industrializado, } \\
\text { não é bom pra nós; bactérias láticas }\end{array}$ \\
\hline
\end{tabular}




\section{Journal of Biochemistry Education}

Revista de Ensino de Bioquímica

Revista de Enseñanza de Bioquímica

REB na escola
64 o.siedade Brasileira de Bioquimica

SSN: 2318-8790

ISSN (until 2012): 1677-2318

\begin{tabular}{|l|l|}
\hline $\begin{array}{l}\text { materiais orgânicos em outros, } \\
\text { liberando energia" }\end{array}$ & $\begin{array}{l}\text { contribuem para nossa saúde, } \\
\text { precisamos delas também" [...] }\end{array}$ \\
\hline $\begin{array}{l}\text { "eu acho que a fermentação é uma } \\
\text { reação que ocorre para fazer o pão" }\end{array}$ & $\begin{array}{l}\text { "Nem tudo que é industrializado é bom } \\
\text { pra nós; bactérias são importantes para } \\
\text { nós, precisamos delas também" [...] }\end{array}$ \\
\hline $\begin{array}{l}\text { "É usado para a industrialização de de } \\
\text { alguns alimentos" }\end{array}$ & $\begin{array}{l}\text { sobre a acidez; sobre as bactérias; } \\
\text { como é feito o iogurte natural; a } \\
\text { necessidade hídrica da Danone }\end{array}$ \\
\hline
\end{tabular}

Quadro 1. Percepção dos alunos antes e depois da aplicação do experimento sobre processo de fermentação.

A tempestade de ideias ou "Brainstorming" é uma técnica usada em dinâmicas de grupo, sua principal característica é explorar as habilidades, potencialidades e a criatividade das pessoas, direcionado ao objetivo de acordo com o interesse. No ensino escolar, essa técnica pôde ser usada como excelente estratégia [25]. A tempestade de ideias permitiu ainda que fosse trabalhada a espontaneidade do aluno em relação aos conhecimentos e se pôde, no caso de aulas práticas, ter uma ideia das transformações que podiam ter sido promovidas a partir do experimento realizado.

No Quadro 2, são mostradas as percepções dos alunos, antes e depois da realização do experimento sobre processo de fotossíntese.

\begin{tabular}{|l|l|}
\hline \multicolumn{1}{|c|}{ ANTES do EXPERIMENTO } & \multicolumn{2}{c|}{ DEPOIS do EXPERIMENTO } \\
\hline $\begin{array}{l}\text { "eu sei que é o nome que se dá à "agora eu sei que as folhas verdes } \\
\text { respiração das plantas [...] serve para } \\
\text { fotossintetizar alimentos" }\end{array}$ & $\begin{array}{l}\text { fazem fotossíntese graças à clorofila, } \\
\text { presentes nas folhas" }\end{array}$ \\
\hline $\begin{array}{l}\text { "É um processo que todas as plantas } \\
\text { fazem" }\end{array}$ & $\begin{array}{l}\text { "É um processo realizado por } \\
\text { organismos produtores, em que se } \\
\text { observa a captura da energia solar e sua } \\
\text { transformação em energia química". }\end{array}$ \\
\hline $\begin{array}{l}\text { "Respiração das plantas; através das } \\
\text { folhas; processo muito importante } \\
\text { para o meio ambiente". }\end{array}$ & $\begin{array}{l}\text { "Seres que fazem fotossíntese: } \\
\text { broduz, algas, plantas. A fotossíntese }\end{array}$ \\
\hline
\end{tabular}

Quadro 2. Percepção dos alunos antes e depois da aplicação do experimento sobre processo de fotossíntese.

No Quadro 3, são apresentadas as percepções dos alunos, antes e depois da realização do experimento sobre processo de respiração.

\begin{tabular}{|l|l|}
\hline \multicolumn{1}{|c|}{ ANTES do EXPERIMENTO } & \multicolumn{1}{c|}{ DEPOIS do EXPERIMENTO } \\
\hline "Nada" & $\begin{array}{l}\text { "O organismo só absorve o açúcar, se } \\
\text { tiver sal junto na mesma quantidade". }\end{array}$ \\
\hline "Não me recordo" & $\begin{array}{l}\text { "É um processo de obtenção de } \\
\text { energia usado pelos seres vivos". }\end{array}$ \\
\hline $\begin{array}{l}\text { "É quando as células precisam de de } \\
\text { oxigênio para sobreviver". }\end{array}$ & $\begin{array}{l}\text { "os fungos com função aeróbia } \\
\text { precisam de uma fonte de glicose para } \\
\text { poder se alimentar". }\end{array}$ \\
\hline
\end{tabular}




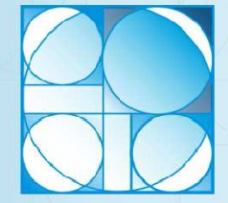

REB na escola
Journal of Biochemistry Education

Revista de Ensino de Bioquímica

Revista de Enseñanza de Bioquímica

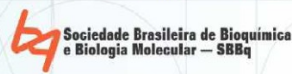

V. 20, N.1 / 2020

Submitted in: 4 jun 2020 Published in: 10 ago 2020

ISSN: 2318-8790

ISSN (until 2012): 1677-2318

Quadro 3. Percepção dos alunos antes e depois da aplicação do experimento sobre a respiração celular aeróbica.

$\mathrm{Na}$ aplicação deste experimento, observou-se a predominância da falta de conhecimento prévio dos alunos sobre o assunto abordado. Desta forma, foram recorrentes as respostas negativas dos alunos antes do experimento (Quadro 3). Esta falta de conhecimento prévio dos alunos pode ser explicada por tratar-se de um tema considerado muito complexo e abstrato, que provavelmente, eles o consideram pouco atraente e sem sentido, talvez por não enxergarem uma relação da respiração celular aeróbica com seu cotidiano. Portanto, a realização de experimentos práticos foi de fundamental importância para melhorar o aprendizado e interesse dos alunos pelo assunto da respiração celular aeróbica.

Em síntese, observou-se dos resultados apresentados após a aplicação dos três experimentos, que os alunos responderam sobre o que já conheciam sobre os temas propostos, porém com respostas baseadas no senso comum. As seguintes afirmações dadas pelos alunos: "fermentação serve para fazer cerveja"; "ela é usada na produção no pão", mostraram que os alunos procuraram definir os processos ministrados a partir de sua realidade e do seu contexto social.

Entretanto, depois da realização dos experimentos, percebeu-se o surgimento de novos questionamentos, os quais permitiram a constatação de quanto os discentes, pouco a pouco, enxergaram a importância e a necessidade da aquisição dos novos conhecimentos, por exemplo, como constatados nas seguintes afirmações: "também precisamos de bactérias para a nossa saúde", "nem tudo que é industrializado é bom", dentre outras.

Assim, foi possível refletir o seguinte:

Se no passado, a escola era o local para obter informações, hoje todos chegam à escola com informações diversas, obtidas na TV, internet ou mesmo pelo rádio. Diante disso, percebe-se que a escola deve se preparar para trabalhar novas habilidades com os estudantes, a fim de que estes tenham uma visão crítica em relação a essas informações, bem como saber comparar, sintetizar essas informações ou então se posicionar com argumentos diante de questões polêmicas. Nesse novo cenário, cabe à escola utilizar as mídias e tecnologias para desenvolver no aluno a habilidade de trabalhar com tantas informações [26]. ${ }^{\text {(p. 379) }}$

\subsection{Avaliação das aulas práticas}

A avaliação das aulas práticas foi dividida em dois blocos. No primeiro bloco, os alunos responderam as questões relacionadas às aulas práticas, de uma forma geral e, sobre os experimentos realizados. No segundo bloco, obteve-se a compreensão dos alunos sobre a metodologia aplicada.Com 


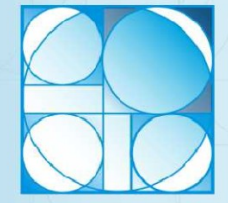

REB na escola
Journal of Biochemistry Education

Revista de Ensino de Bioquímica

Revista de Enseñanza de Bioquímica

64 Sociedade Brasileira de Bioquimica
V. 20, N.1 / 2020

Submitted in: 4 jun 2020 Published in: 10 ago 2020

a Figura 1, mostrou-se o conhecimento prévio dos alunos com relação aos microrganismos e seus benefícios para os seres humanos.

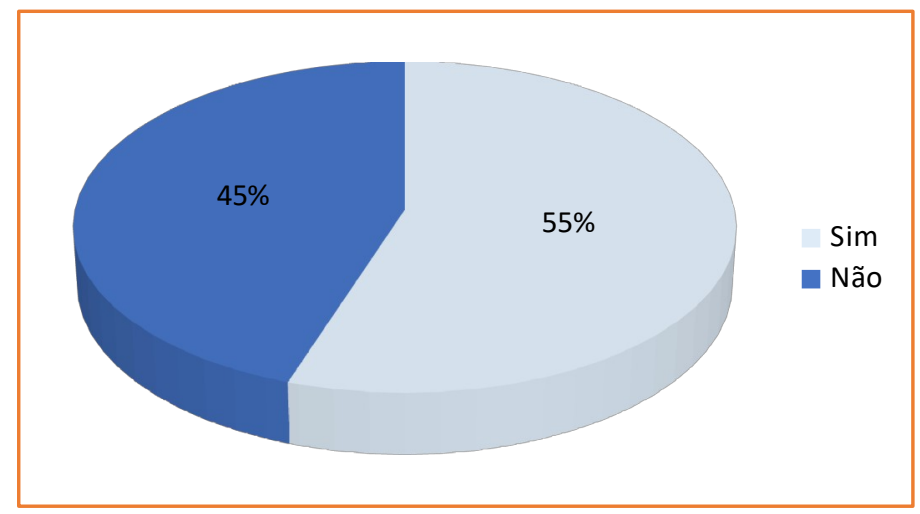

Figura 1. Conhecimento prévio dos alunos sobre microrganismos e seus benefícios a saúde dos seres humanos.

Constatou-se, com a Figura 1, a existência de um equilíbrio nas porcentagens das respostas obtidas entre os alunos que conheciam os benefícios dos microrganismos à saúde humana (45\%) e, daqueles que não conheciam estes benefícios (55\%). Estes dados foram diferentes dos encontrados na pesquisa realizada por Antunes, Pileggi e Pazda [27], que ao questionarem alunos do ensino médio de uma escola no Paraná, estes, manifestaram a necessidade de aprender sobre os microrganismos para evitarem contaminação e se prevenirem de doenças (88\%) e, por outro lado, apenas $12 \%$ afirmaram que os microrganismos traziam benefícios aos seres humanos.

Com a Figura 2, apresentou-se o conhecimento prévio dos alunos com relação à fabricação de produtos lácteos.

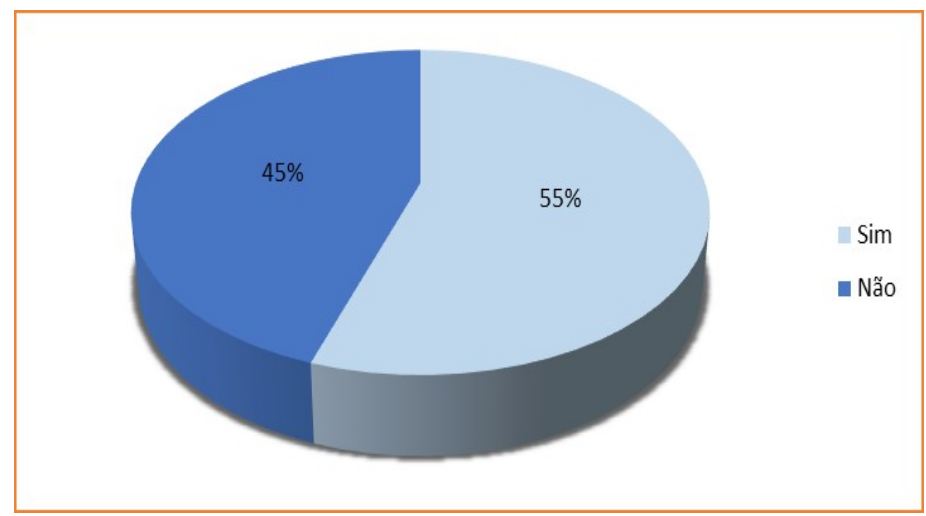

Figura 2. Conhecimento prévio dos alunos sobre fabricação de produtos lácteos. Fonte: próprio autor.

Os resultados encontrados foram semelhantes aqueles obtidos à pergunta anterior. Dentre os 


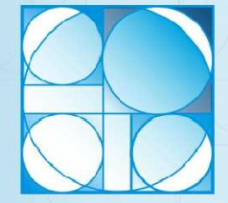

REB na escola
Journal of Biochemistry Education

Revista de Ensino de Bioquímica

Revista de Enseñanza de Bioquímica

64 Sociedade Brasileira de Bioquimica
V. 20, N.1 / 2020

Submitted in: 4 jun 2020 Published in: 10 ago 2020

$55 \%$ dos alunos que responderam positivamente ao conhecimento prévio sobre a fabricação de produtos lácteos, as respostas mais recorrentes foram sobre fabricação de queijo, requeijão e iogurte. Este conhecimento prévio apresentado pela maioria dos discentes possivelmente foram provenientes de outras aulas práticas. Ademais, quando os alunos foram questionados com que frequência ocorriam aulas práticas na escola, enquanto $66 \%$ afirmaram que tinham mais de 5 aulas/ano, 34\% responderam que tiveram menos de 5 aulas/ano (Figura 3 ).

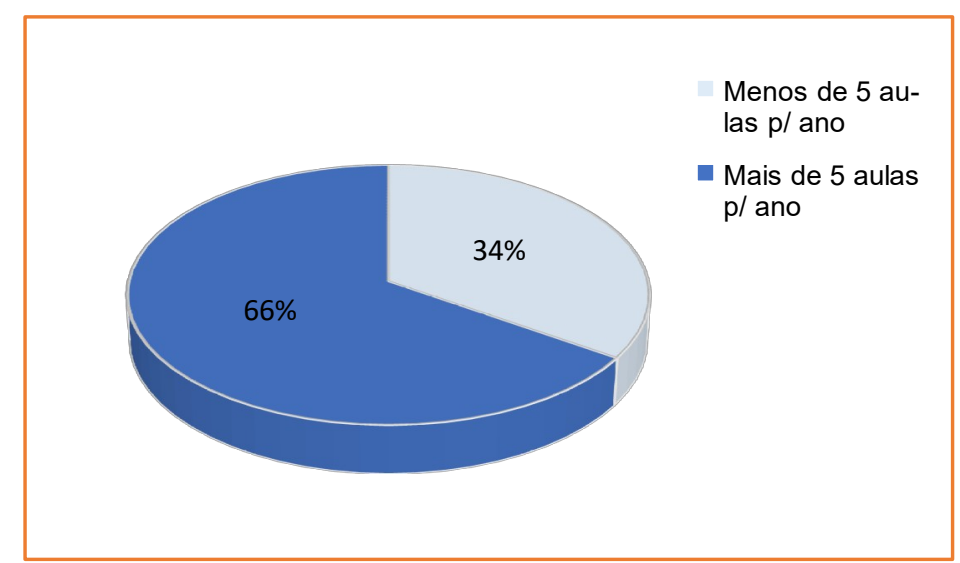

Figura 3. Frequência dos alunos em aulas práticas no período letivo.

Com a Figura 4, mostrou-se qual é o modelo de aula prática em que o aluno considera que aprende mais a Biologia.

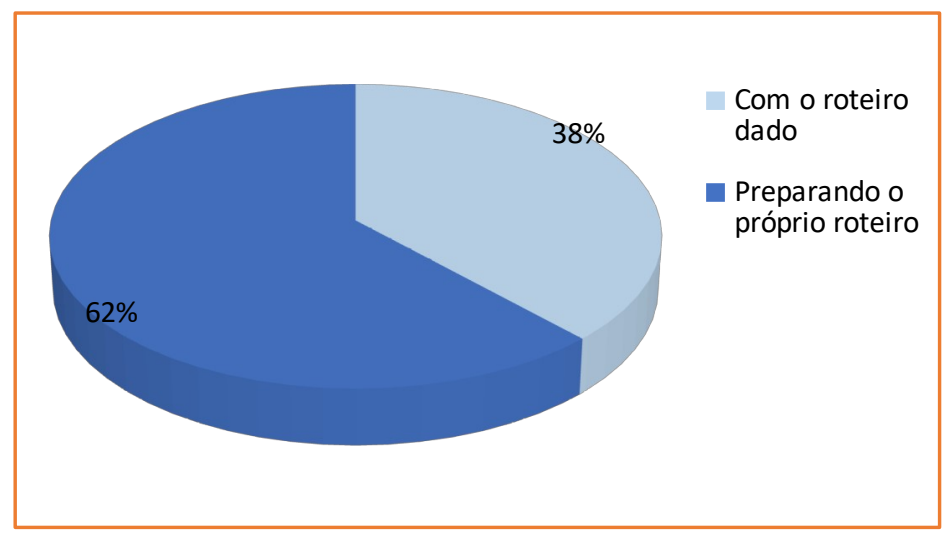

Figura 4. Modelo de aula prática que o aluno considera que aprende mais facilmente a Biologia.

Com a Figura 4, notou-se que maioria dos alunos (62\%) manifestou a vontade de protagonizar nos momentos de aulas práticas, ou seja, de poderem sugerir, planejar, participar de forma mais ativa do processo de ensino-aprendizagem, sendo algo que o professor deveria 


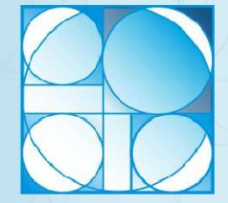

REB na escola

\section{Journal of Biochemistry Education}

Revista de Ensino de Bioquímica

Revista de Enseñanza de Bioquímica

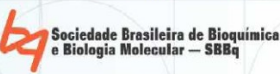

V. 20, N.1 / 2020

Submitted in: 4 jun 2020 Published in: 10 ago 2020

levar em consideração no planejamento desta atividade. Quando os discentes foram questionados se os conteúdos abordados nas aulas práticas, deveriam ser introduzidos antes ou depois da realização destas, as respostas obtidas foram as apresentadas na Figura 5.

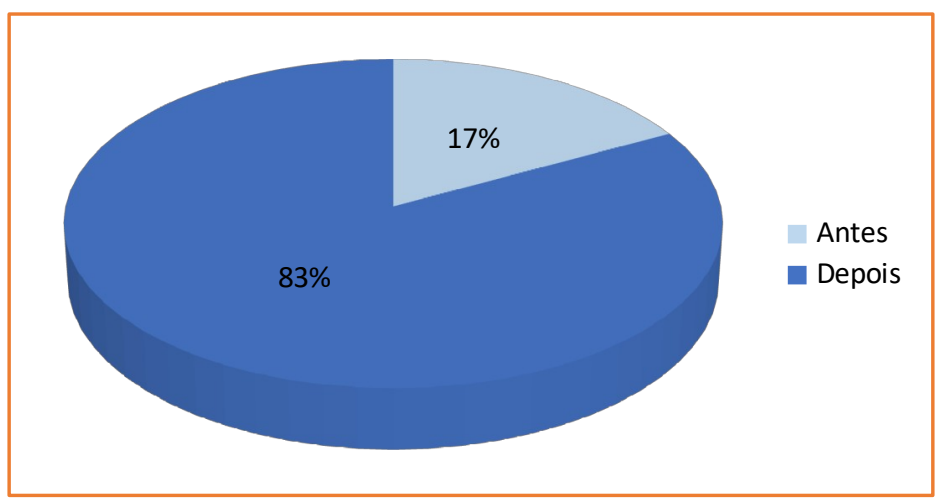

Figura 5. Opinião dos alunos sobre a exposição do conteúdo antes ou depois da aula prática.

Apesar da constatação de que a grande maioria dos alunos $(83 \%)$ consideraram que a inserção de aulas práticas deveriam acontecer após os conteúdos do tema serem explanados, é importante salientar que a realização de uma atividade prática não tem um "momento certo" para ocorrer, pois dependendo do assunto, o docente pode planejar realizá-la no momento que julgar mais conveniente, para que ocorra um melhor entendimento e aprendizagem dos discentes.

No segundo bloco, foi aplicado um questionário específico (APÊNDICE C - materiais adicionais) para avaliar a percepção dos alunos sobre a metodologia aplicada, contendo 12 perguntas, cujas respostas foram mensuradas, empregando a escala hedônica de cinco pontos/conceitos.

Com a Figura 6, apresentou-se os resultados de todas as perguntas considerando o aspecto global nos experimentos realizados.

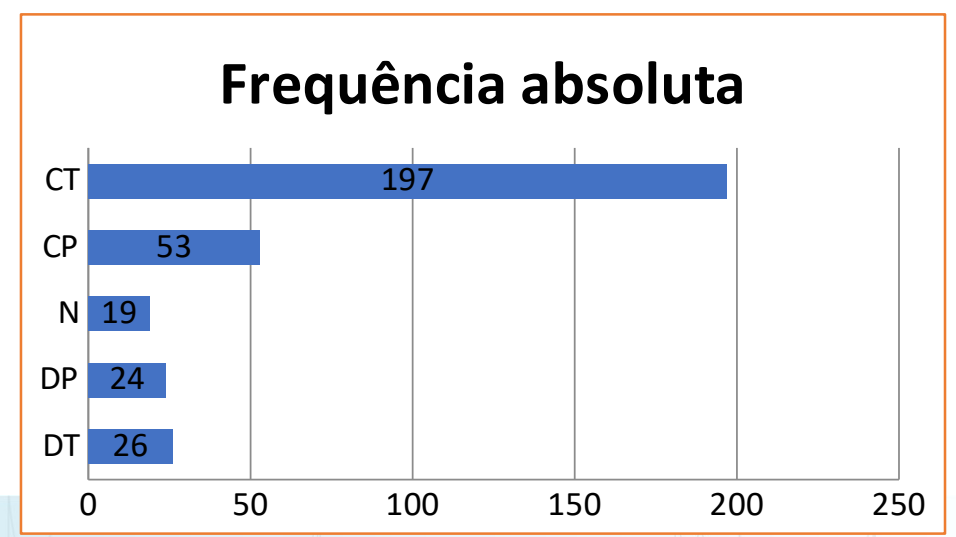




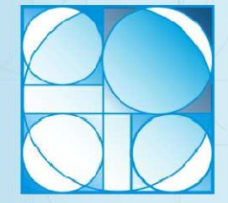

REB na escola
Journal of Biochemistry Education

Revista de Ensino de Bioquímica

Revista de Enseñanza de Bioquímica

64 Sociedade Brasileira de Bioquimica
V. 20, N.1 / 2020

Submitted in: 4 jun 2020 Published in: 10 ago 2020

ISSN: 2318-8790

ISSN (until 2012): 1677-2318

Figura 6. Visão geral dos resultados de todas as perguntas aos alunos sobre os experimentos realizados, expresso em escala hedônica de cinco pontos.

Onde: 1- Discordo Totalmente - DT; 2- Discordo Parcialmente - DP; 3- Sem opinião formada - N; 4- Concordo Parcialmente - CP; 5- Concordo Totalmente - CT.

Percebeu-se, na Figura 6, o predomínio de respostas positivas dos discentes em relação a todos os experimentos realizados, haja vista que os conceitos CP e CT obtiveram uma soma igual a $78,4 \%$. Entretanto, o conceito $\mathrm{N}$ foi obtido em um total de 19 respostas, com porcentagem de 5,9\%, já os conceitos DP e DT, que representavam as respostas negativas, somaram apenas $15,7 \%$.

Com a Figura 7, apresentou-se a avaliação da aula prática como facilitadora do processo de aprendizagem dos alunos.

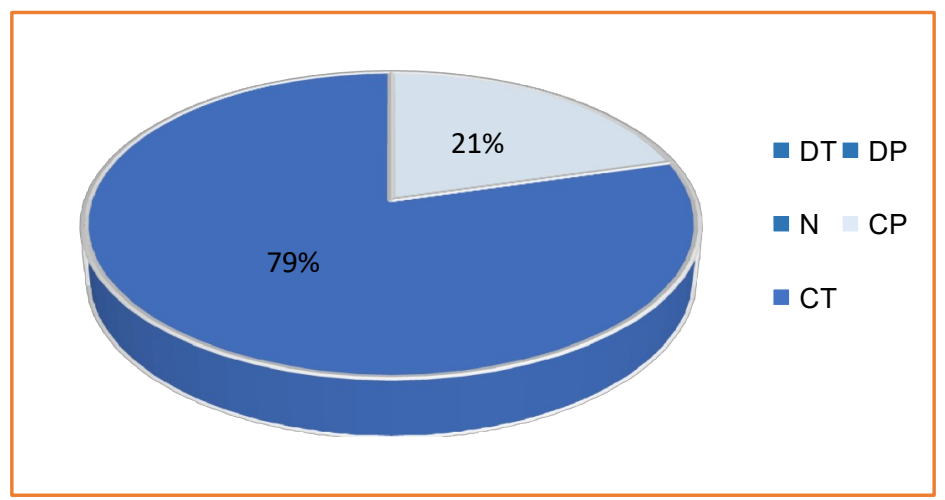

Figura 7. Aulas práticas como facilitadoras do processo de aprendizagem.

Legenda: Discordo Totalmente - DT; Discordo Parcialmente - DP; Sem opinião formada - N; Concordo Parcialmente - CP; Concordo Totalmente - CT.

A maioria dos alunos (79\%) concordou que as aulas práticas são facilitadoras do processo de aprendizagem de conteúdos de Bioquímica e Microbiologia (Figura 7).

Os resultados da pesquisa de Lima e Garcia [28], que estudaram alunos de ensino médio de quatro escolas de Porto Alegre - RS, cujo questionamento aos alunos assemelha-se a este estudo, mostraram que a grande maioria respondeu afirmativamente, observando esta resposta até entre os alunos que jamais tiveram qualquer contato com aulas práticas.

Os resultados encontrados nesta pesquisa, embora, sejam elementares, são importantes, quando se constata como sendo natural, que as aulas práticas despertem maior interesse nos alunos, sobretudo, quando ainda prevalecem no cotidiano de muitas escolas, aulas permeadas pela abordagem de ensino tradicional com aulas expositivas, uso predominante do livro didático, exercícios de fixação, dentre outros. Portanto, é esperado que ocorra uma maior motivação do aluno, quando ele se depara com estratégias de ensino com situações concretas do conhecimento. 


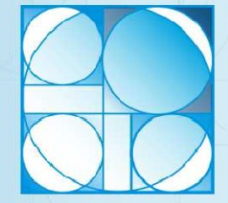

REB na escola
Journal of Biochemistry Education

Revista de Ensino de Bioquímica

Revista de Enseñanza de Bioquímica

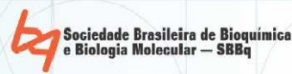

V. 20, N.1 / 2020

Submitted in: 4 jun 2020 Published in: 10 ago 2020

ISSN: 2318-8790

ISSN (until 2012): 1677-2318

Neste contexto, as aulas práticas podem ser facilitadoras da aprendizagem, principalmente, quando elas se inserem de forma a responder três questões básicas: $\mathbf{O}$ que é estudado? Onde ocorre este fenômeno? Para que serve na vida cotidiana?

Os alunos foram questionados, se, ao serem participantes do processo, se sentiram mais autônomos e independentes no que diz respeito ao aprendizado. Percebeu-se que sim, pelo grande número de respostas positivas da Figura 8.

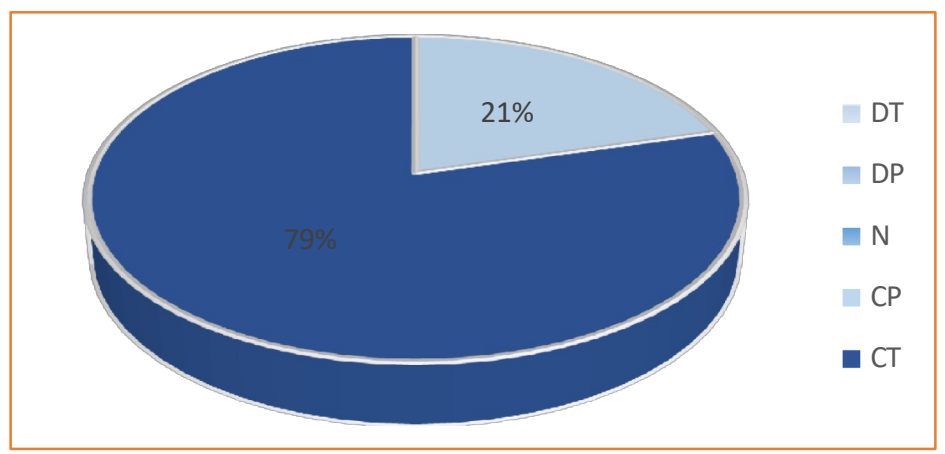

Figura 8. Aulas práticas como promotoras da autonomia e independência.

Legenda: Discordo Totalmente - DT; Discordo Parcialmente - DP; Sem opinião formada - N; Concordo Parcialmente - CP; Concordo Totalmente - CT.

Evidenciou-se, que ao protagonizar a construção do próprio conhecimento, o aluno sentiu-se mais valorizado e acabou tendo a percepção maior das mudanças que as aulas práticas proporcionaram, estimulando-o a ser o agente na elaboração do conhecimento e na percepção crítica dos saberes.

Com base nesse protagonismo do aluno, fez-se necessária a discussão sobre a necessidade de dar mais atenção no ensino de Biologia ao aspecto de prática social.

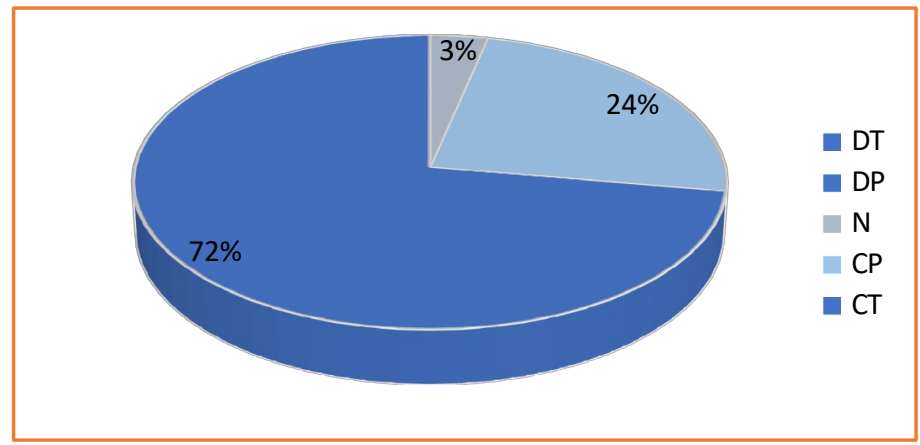

Figura 9. Preferência dos alunos quanto à modalidade de aulas práticas.

Legenda: Discordo Totalmente - DT; Discordo Parcialmente - DP; Sem opinião formada - N; Concordo

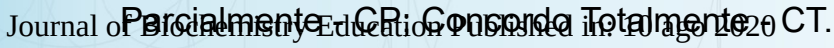




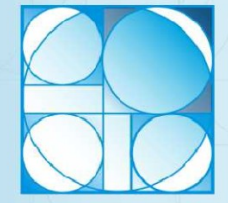

REB na escola
Journal of Biochemistry Education

Revista de Ensino de Bioquímica

Revista de Enseñanza de Bioquímica

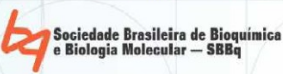

V. 20, N.1 / 2020

Submitted in: 4 jun 2020 Published in: 10 ago 2020

Verificou-se que $72 \%$ dos alunos concordaram totalmente que as aulas práticas são melhores que as aulas convencionais, corroborando com os resultados discutidos anteriormente, sobre o interesse que esse tipo de aula desperta nos alunos, contribuindo, além da construção do conhecimento, para sua autonomia e formação cidadã (Figura 9).

Alguns pesquisadores na área das Ciências destacaram, em seus estudos, a necessidade de educar o homem para a cidadania responsável, por meio de uma alfabetização que contemple uma formação científica. Para eles, a escola é o ambiente cultural apropriado para se iniciar o processo que permita aos cidadãos a obtenção de informações e o desenvolvimento da capacidade crítica [29].

No que se refere às dificuldades dos alunos para formular questionamentos sobre os assuntos abordados nas aulas práticas, os resultados foram os apresentados na Figura 10.

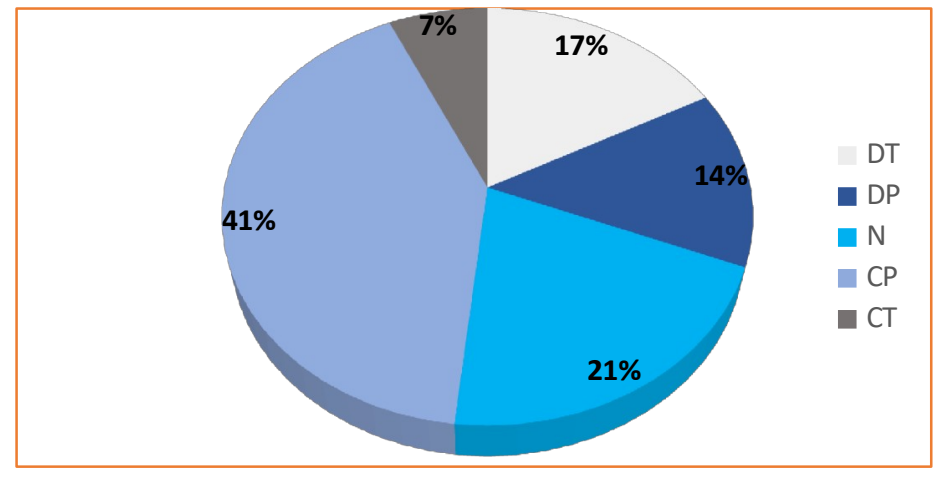

Figura 10. Dificuldades dos alunos em formular questionamentos.

Legenda: Discordo Totalmente - DT; Discordo Parcialmente - DP; Sem opinião formada - N; Concordo Parcialmente - CP; Concordo Totalmente - CT.

Constatou-se que $41 \%$ dos alunos sentiram dificuldades em fazer questionamentos; $21 \%$ afirmaram não ter opinião formada sobre no assunto e 17\% discordaram totalmente com esta afirmação (Figura 10).

A Biologia é um campo da ciência que, frequentemente, desperta questionamentos por parte dos alunos, que querem saber sobre temas atuais, como as células-tronco, organismos geneticamente modificados, dentre outros. Eles questionam não somente conceitos, mas, o desenvolvimento das experiências, os pontos positivos e negativos, os resultados, dentre outros. São questões científicas e tecnológicas que, embora estejam constantemente sendo abordadas nos mais diversos espaços e traduzam uma convivência com as inovações tecnológicas necessitam de um embasamento científico para as respostas [29,32].

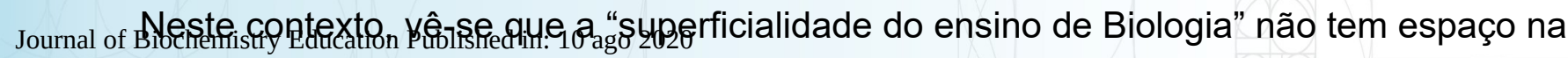




\section{Journal of Biochemistry Education}

\section{Revista de Ensino de Bioquímica}

Revista de Enseñanza de Bioquímica

REB na escola

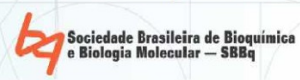

V. 20, N.1 / 2020

Submitted in: 4 jun 2020 Published in: 10 ago 2020

ISSN: 2318-8790

ISSN (until 2012): 1677-2318

escola e, portanto, faz-se necessário que os professores deem a esse ensino outras funções, fora daquelas que, por tradição, fazem-se presente no currículo escolar.

Na Figura 11, observou-se que 52\% dos alunos responderam discordar totalmente (DT) em terem tido alguma dificuldade, enquanto um número considerável de alunos (28\%) afirmaram que concordam totalmente (CT), demostrando que, apesar da maioria não ter tido dificuldades, um número considerável de alunos (28\%) apresentaram algumas dificuldades em criar os experimentos.

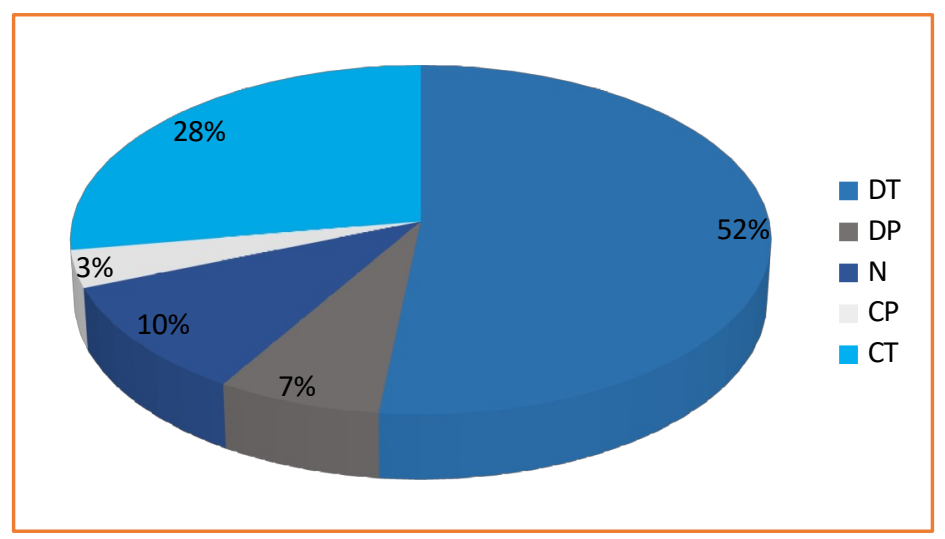

Figura 11. Dificuldades dos alunos em criar os experimentos.

Legenda: Discordo Totalmente - DT; Discordo Parcialmente - DP; Sem opinião formada - N; Concordo Parcialmente - CP; Concordo Totalmente - CT.

No ensino de Biologia e mais especificamente de conteúdos que envolvem conhecimentos de novas biotecnologias, viu-se a exigência de alterações, inclusões nos programas de ensino e nas atividades pedagógicas, o que não precisa, necessariamente, implicar em uma mudança radical de currículo, como:

(...) Saber articular os conteúdos científicos obrigatórios no currículo; as teorias de aprendizagem da Ciência; a seleção de atividades diversificadas capazes de motivar os alunos a reelaborarem as informações; a orientação das atividades (enquanto docentes), e a avaliação dos resultados (enquanto pesquisadores). [30] ${ }^{\text {p.73 }}$

Krasilchik [31], descrevendo os objetivos do ensino de Biologia, aponta que são: "aprender conceitos básicos, analisar o processo de pesquisa científica e analisar as implicações sociais da ciência e da tecnologia". Segundo esta autora, "a Biologia pode ser uma das disciplinas mais relevantes e merecedoras da atenção dos alunos, ou uma das disciplinas mais insignificantes e pouco atraentes, dependendo do que for ensinado e de como isso for feito".

Em relação ao interesse dos alunos em participar de aulas práticas, a Figura 12 Journal of Biochemistry Education Published in: 10 ago 2020 


\section{Journal of Biochemistry Education}

\section{Revista de Ensino de Bioquímica}

Revista de Enseñanza de Bioquímica

REB na escola

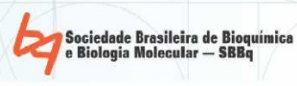

ISSN: 2318-8790

ISSN (until 2012): 1677-2318

mostrou que a maioria dos alunos concorda totalmente com esta afirmação.

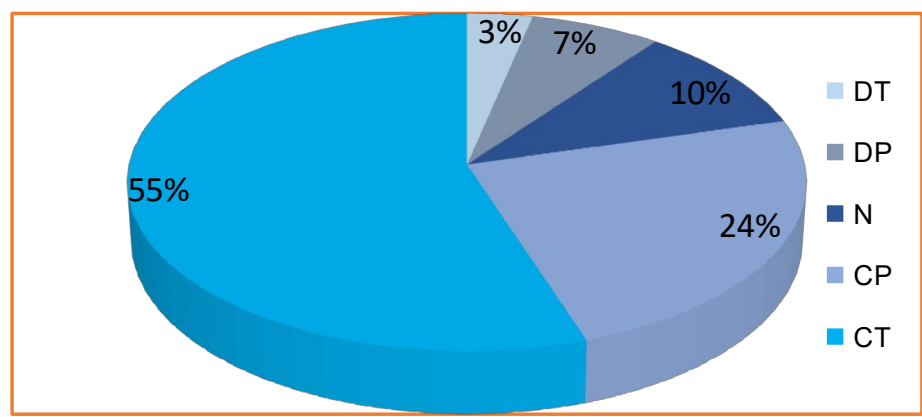

Figura 12. Interesse dos alunos em participar de aulas práticas na escola.

Legenda: Discordo Totalmente - DT; Discordo Parcialmente - DP; Sem opinião formada - N; Concordo Parcialmente - CP; Concordo Totalmente - CT.

Observou-se, na Figura 12, que 55\% concordaram parcialmente e $24 \%$ concordaram totalmente (soma CP $+\mathrm{CT}=79 \%$ ), sendo que $10 \%$ dos alunos não têm opinião formada sobre o assunto e apenas uma pequena parcela (soma=11\%) discorda totalmente (4\%) e parcialmente $(7 \%)$, pelo interesse em aulas práticas.

Vale salientar que o interesse do aluno em participar de aulas práticas tem relação direta com o tipo de conteúdo, atividades, experimentos e outros métodos utilizados. Por mais que alunos realmente gostem do que denominam "de aulas diferentes", se elas não forem providas de sentido e significado, estas serão apenas uma forma de cumprir a tarefa em um período pré-determinado.

Por esta razão, as duas perguntas seguintes apontaram para eventuais mudanças que as aulas práticas podiam ter trazido para a vida dos alunos, quando, primeiro, são questionados se os conhecimentos adquiridos nessas aulas ajudariam para que tivessem uma alimentação saudável e, segundo se ajudaria a evitar doenças. Em síntese, as aulas promoveriam alguma mudança na vida desses alunos?

Nas Figuras 13 e 14, apresentaram-se as respostas destas perguntas.

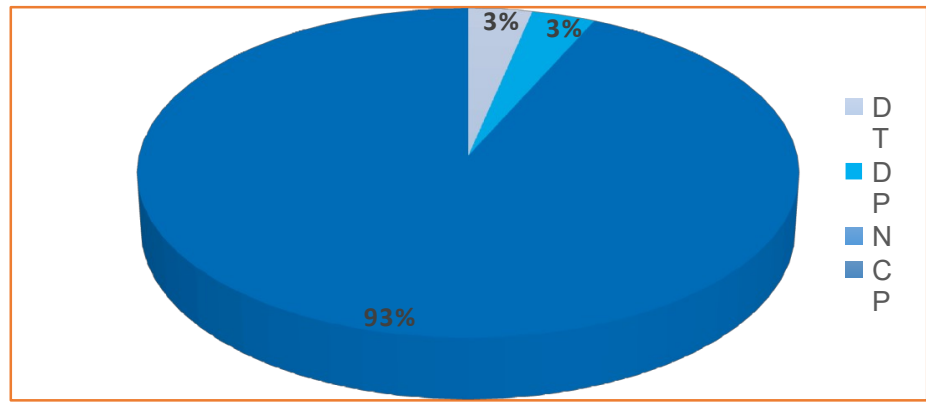

Figura 13. Promoção de alimentação saudável com os conhecimentos adquiridos por meio dos experimentos Journal of Biochemistry Education Published in: 10 ago 2020 


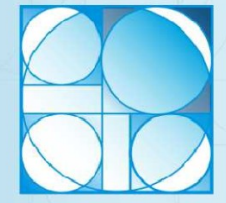

REB na escola
Journal of Biochemistry Education

Revista de Ensino de Bioquímica

Revista de Enseñanza de Bioquímica

64 Sociedade Brasileira de Bioquimica
V. 20, N.1 / 2020

Submitted in: 4 jun 2020 Published in: 10 ago 2020

ISSN: 2318-8790

ISSN (until 2012): 1677-2318

práticos na escola.

Legenda: Discordo Totalmente - DT; Discordo Parcialmente - DP; Sem opinião formada - N; Concordo Parcialmente - CP; Concordo Totalmente - CT.

Verificou-se, na Figura 13, que 93\% dos alunos afirmaram a importância de realização de aulas práticas, com este tipo de experimentos e, que ajudaram a promover uma alimentação mais saudável.

$\mathrm{Na}$ Figura 14, representou-se a visão dos alunos que participaram dos experimentos, com relação à prevenção de doenças.

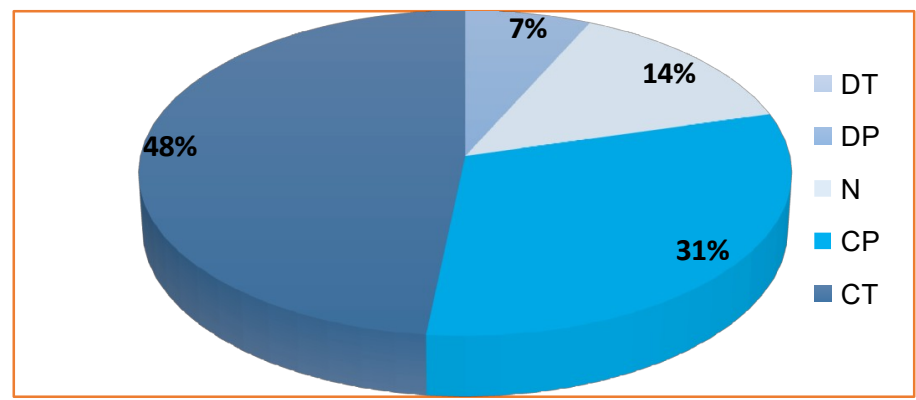

Figura 14. Promoção da prevenção de doenças com os conhecimentos adquiridos por meio dos experimentos práticos na escola.

Legenda: Discordo Totalmente - DT; Discordo Parcialmente - DP; Sem opinião formada - N; Concordo Parcialmente - CP; Concordo Totalmente - CT.

Observou-se que $79 \%$ dos alunos (soma CP $+\mathrm{CT}$ ) acreditaram que as aulas práticas na escola poderiam promover sua qualidade de vida (Figura 14).

Os alunos participando dos experimentos e compreendendo mais sobre Bioquímica e Microbiologia poderiam trazer para a sua realidade os conhecimentos que antes eram somente conteúdos didáticos não relacionados ao seu cotidiano. Logo o aluno despertaria e compreenderia que os conhecimentos em Biologia ou em qualquer outra área se fazem presentes em sua vida cotidianamente.

Lousan [32], ao analisar os desafios do professor de Biologia diante da inserção de metodologias ativas de aprendizagem, viu a partir do que observou da percepção de professores e alunos de uma escola pública, que os temas relacionados à saúde que mais despertam o interesse dos alunos são aqueles relacionados ao seu cotidiano, que valorizam seus saberes prévios, destacando a importância da utilização de recursos e métodos de ensino variados, como os experimentos em aulas práticas. Na percepção da autora, é possível promover mudanças importantes na vida dos alunos, por meio de métodos adequados e assertivos para sua vida cotidiana.

Diante da evidente constatação, ao longo da pesquisa, de que os alunos reconhecem a importância das aulas práticas de Biologia, quisemos saber deles se este método é utilizado também, em outras disciplinas, e as respostas foram representadas na Figura 15. 


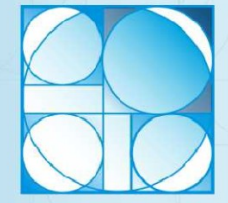

REB na escola
Journal of Biochemistry Education

Revista de Ensino de Bioquímica

Revista de Enseñanza de Bioquímica

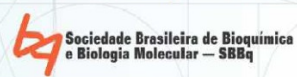

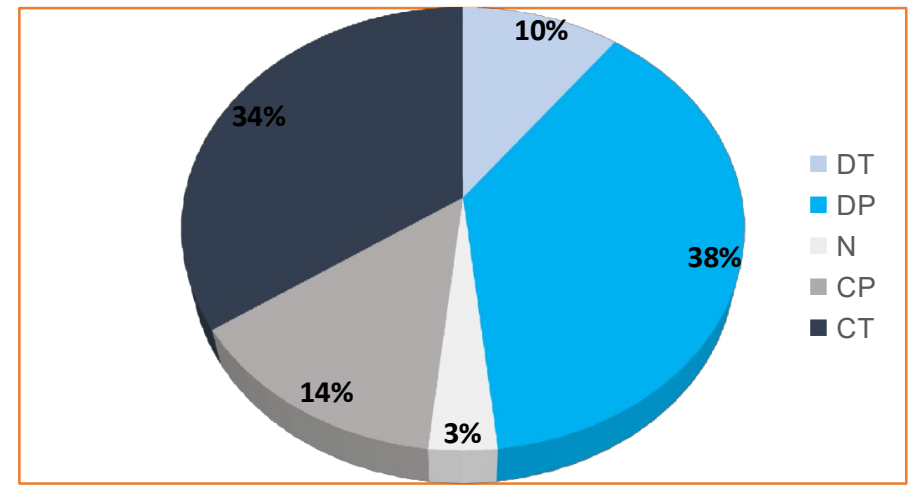

V. 20, N.1 / 2020

Submitted in: 4 jun 2020 Published in: 10 ago 2020

ISSN: 2318-8790

ISSN (until 2012): 1677-2318

Figura 15. Existência de aulas práticas em outras disciplinas.

Legenda: Discordo Totalmente - DT; Discordo Parcialmente - DP; Sem opinião formada - N; Concordo Parcialmente - CP; Concordo Totalmente - CT.

Observou-se, na Figura 15, que os alunos se mostraram bem divididos em relação a esta questão, sendo que 38\% discordaram parcialmente e 35\% concordaram totalmente, que as aulas práticas ocorrem em outras disciplinas.

É fundamental destacar que as aulas práticas podem ser inseridas em qualquer área de conhecimento, e sobretudo, serem desenvolvidas sob a abordagem interdisciplinar, visto que as áreas de saberes dialogam entre si, não havendo um campo isolado de conhecimento.

Fato importante a ser destacado desta pesquisa é o trabalho e o papel que o docente desempenha neste processo de ensino e aprendizagem. Como facilitador deste processo, cabe ao docente a maior responsabilidade pelo êxito ou fracasso dos resultados, pois é ele quem planeja, orienta e media a realização das aulas práticas.

Quando o (a) professor(a) percebe o êxito de suas iniciativas em sala de aula, assumirá uma postura mais segura e se sentirá mais entusiasmado com as aulas, pois:

É o professor que propõe problemas a serem resolvidos, que irão gerar ideias que, sendo discutidas, permitirão a ampliação dos conhecimentos prévios; promove oportunidade para reflexão, indo além das atividades puramente práticas; estabelece métodos de trabalhos colaborativos e um ambiente na sala de aula em que todas as ideias são respeitadas [33]. ${ }^{\text {p.36 }}$

Assim, cabe ao professor tornar o processo de aprendizagem mais motivador, pois é a partir de sua ação, da forma como estabelece o seu método de ensino, que a atividade prática proposta terá ou não sentido para o aluno.

Libâneo [34, p. 105] preconiza que "o trabalho docente somente é frutífero quando o ensino dos conhecimentos e dos métodos de adquirir e aplicar conhecimentos se convertem em conhecimentos, habilidades, capacidades e atitudes do aluno", ou seja, quando a aprendizagem se realiza, de 


\section{Journal of Biochemistry Education}

\section{Revista de Ensino de Bioquímica}

Revista de Enseñanza de Bioquímica

REB na escola

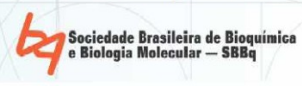

V. 20, N.1 / 2020

Submitted in: 4 jun 2020 Published in: 10 ago 2020

ISSN: 2318-8790

ISSN (until 2012): 1677-2318

forma prática, fazendo sentido para o aluno e cumprindo sua ação transformadora.

A ideia do ensino despertado pelo interesse do estudante, passou a ser um desafio à competência do docente, pois precisa estabelecer as relações necessárias, com aulas que estimulem, motivem e façam conexões entre o conhecimento cotidiano e o científico, transformando-o em conhecimento escolar, para que o processo de ensino-aprendizagem seja eficaz, com uma metodologia adequada [35].

Morin [36], que defende os setes saberes necessários à educação do futuro, afirma que, para compreender a contextualização do ensino deve-se procurar, antes, compreender a contextualização do conhecimento. Pode-se perceber, a partir do que apresenta o autor, que é necessária a reflexão sobre esse conhecimento contextualizado, tendo em vista que:

[...] não ensinamos as condições de um conhecimento pertinente, isto é, de um conhecimento que não mutila o seu objeto. Nós seguimos, em primeiro lugar, um mundo formado pelo ensino disciplinar. É evidente que as disciplinas de toda ordem ajudaram o avanço do conhecimento e são insubstituíveis. O que existe entre as disciplinas é invisível e as conexões entre elas também são invisíveis. Mas isto não significa que seja necessário conhecer somente uma parte da realidade. É preciso ter uma visão capaz de situar o conjunto. É necessário dizer que não é a quantidade de informações, nem a sofisticação em Matemática que podem dar sozinhas um conhecimento pertinente, mas sim a capacidade de colocar o conhecimento no contexto. [36 ${ }^{\text {p. 03] }}$

Portanto, Morin [36] chama nossa atenção para algo interessante, quando enfatiza que não é a quantidade de conteúdo, nem os meios sofisticados que irão proporcionar a aprendizagem significativa do aluno, mas, sobretudo, o conhecimento inserido dentro do contexto.

\section{Considerações Finais}

Os resultados encontrados nesta pesquisa foram relevantes na medida em que reforçam que as aulas práticas, quando ministradas com abordagem interdisciplinar, despertam maior interesse nos alunos.

Nesta pesquisa, constatou-se ainda que os recursos tecnológicos e os laboratórios bem equipados não são essenciais para implantação de uma metodologia ativa. Estes são importantes, sem dúvida para seu êxito, mas não podem ser fatores limitantes, como ficou evidente ao longo deste estudo.

O estudo mostrou também, que é possível promover mudanças na qualidade de vida dos alunos a partir dos conhecimentos ministrados nas aulas práticas de Biologia, como parte do plano de aula. 


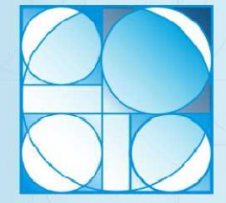

REB na escola
Journal of Biochemistry Education

Revista de Ensino de Bioquímica

Revista de Enseñanza de Bioquímica

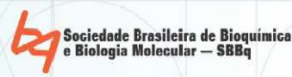

V. 20, N.1 / 2020

Submitted in: 4 jun 2020 Published in: 10 ago 2020

ISSN: 2318-8790

ISSN (until 2012): 1677-2318

Entretanto, ficou evidente que os alunos do ensino médio apresentaram algumas dificuldades em lidar com as aulas práticas desses conhecimentos, porque sempre foram apresentados a eles de forma mecânica.

Conclui-se que o ensino de Bioquímica e Microbiologia por meio de aulas práticas com uma abordagem interdisciplinar teve importante impacto no aprendizado dos alunos, e trouxeram subsídios para a continuidade desse processo, traduzindo-se em construção de conhecimentos, motivação, interesse e facilitação da aprendizagem, e promoção da qualidade de vida dos alunos.

\section{Referências}

[1] Da Poian AT, Braga, CACA, Ketzer, LA. Energy transformation in the living organisms. Journal Biochemistry Education, 2017; 15 (esp): 126-154.

[2] Silva, T, Galembeck, E. Developing and supporting students' autonomy to plan, perform, and interpret inquiry-based biochemistry experiments. J. Chem. Educ., 2017; 94 (1): 52-60.

[3] Bombonato, LGG. A importância do uso do laboratório nas aulas de ciências. Medianeira. Trabalho Conclusão Curso [Especialização em Ensino de Ciências] - Universidade Tecnológica Federal do Paraná, 2011.

[4] Carraher, D. Educação tradicional e educação moderna. In: Carraher, TN (Org.). Aprender pensando: contribuições da psicologia cognitiva para a educação. Petrópolis, RJ: Vozes; 1986.

[5] Lima, KEC; Vasconcelos, SD. Análise da metodologia de ensino de ciências nas escolas da rede municipal de Recife. Ensaio: avaliação e políticas públicas em educação, 2006; 14 (52), 397- 412 .

[6] Moreira, LC, Sousa, GS. O uso de atividades investigativas como estratégia metodológica no ensino de microbiologia: um relato de experiência com estudantes do ensino médio. Exper. Ensino de Ciências, 2016; 11(3): 1-17.

[7] OCDE. Programme for international student assessment (Pisa). Country note Brazil, 2018. [lacesso em 20 mai 2020]. Disponível em: https://www.oecd.org/pisa/publications/PISA2018_CN_BRA.pdf

[8] Barbosa, EF, Moura, DG. Metodologias ativas de aprendizagem na educação profissional e tecnológica. Bol. Tec. Senac. Rio de Janeiro. 2013; 39 (2): 48-67.

[9] Venturi, T, Clebsch, AB, De Luca, AG. Interdisciplinaridade no ensino de ciências: possibilidades e desafios para a formação de professores. Revista da Sociedade Brasileira de Ensino em Biologia, 2016; 9: 305-318. 


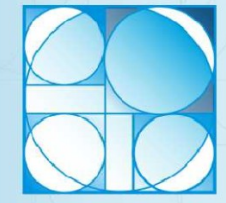

REB na escola
Journal of Biochemistry Education

Revista de Ensino de Bioquímica

Revista de Enseñanza de Bioquímica

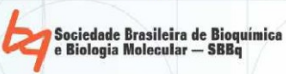

V. 20, N.1 / 2020

Submitted in: 4 jun 2020 Published in: 10 ago 2020

[10] Depresbiteris, L, Tavares, MR. Diversificar é preciso... instrumentos e técnicas de avaliação de aprendizagem. São Paulo: Senac; 2017.

[11] Machado, MS, Ricardo, J, Sugai, JK, Figueiredo, MSRB, Antônio, RV, Heidrichet, DN. Bioquímica através da animação. Florianópolis: UFSC, 2010. [acesso em 15 julho 2019]. Disponível em: https://periodicos.ufsc.br/index.php/extensio/article/view/1081/4358

[12] Rodrigues, BCR, Galembeck, E. Aminoácidos e proteínas: proposta de atividade prática sob uma abordagem investigativa. Revista de Ensino de Bioquímica, 2011; 9 (1): 41-50.

[13] Moresco,TR, Barbosa, NV, Rocha, JBT. Ensino de microbiologia e a experimentação no ensino fundamental. Revista contexto \& educação; 2017; 32 (103): 165-190. Doi: https://doi.org/ 10.21527/2179-1309.2017.103.165-190

[14] Madigan, MT, Martinko, JM, Dunlap, PV, Clark, DP. Microbiologia de Brock. 14 ed. Porto Alegre: Artmed, 2016.

[15] Kimura, AH, Oliveira, GS, Scandorieiro, S, Souza, PC, Schuruff, PA, Medeiros, L P, et al. Microbiologia para o ensino médio e técnico: contribuição da extensão ao ensino e aplicação da ciência. Revista Conexão UEPG, 2013; 9 (2): 254-267.

[16] Tortora, GJ, Funke, BR, Case, C. L. Microbiologia. 12 ed. Porto Alegre: Artmed, 2017.

[17] Barbosa, FHF, Barbosa, LPJL. Alternativas metodológicas em microbiologia: viabilizando atividades práticas. Revista de Biologia e Ciências da Terra 2010; 10(2): 134-143.

[18] Dal-Farra, RA, Lopes, PTC. Métodos mistos de pesquisa em educação: pressupostos teóricos. Revista Nuances: estudos sobre Educação, 2013; 24 (3): 67-80.

[19] Hamze, A. Brainstorming como exercício de criatividade. [acesso em 17 nov 2019]. Disponível em: https://educador.brasilescola.uol.com.br/trabalho-docente/brainstorming.htm

[20] Brasil, Conselho Nacional de Saúde. Resolução n466, 12 dezembro 2012. Diário Oficial da União de 13 de jun 2013; Seção 1: 59.

[21] Ordóñez, JA (org), Rodríguez, MIC, Álvarez, LF, Sanz, MLG, Minguillón, GGF, Perales, LH, et al. Tecnologia de alimentos. vol.2 - Alimentos de origem animal. São Paulo: Artmed; 2005.

[22] Carvalho, AA, Vilas-Boas, A. Fotossíntese: o "alimento" da planta - história e experimentos. Portal do professor. [acesso em 15 mar 2019] Disponível em: http://portaldoprofessor.mec.gov.br/fichaTecnicaAula.html?aula=51700

[23] Castagini, AS. Por que sinto câimbras? Respiração celular. Portal do professor. [acesso em 15 mar 2019] Disponível em: http://portaldoprofessor.mec.gov.br/fichaTecnicaAula.html?aula=4865

[24] Minin, VPR. Análise sensorial: Estudos com consumidores. Viçosa-MG: Universidade Journal of Biochemistry Education Published in: 10 ago 2020 


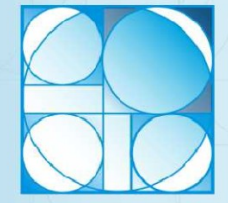

REB na escola
Journal of Biochemistry Education

Revista de Ensino de Bioquímica

Revista de Enseñanza de Bioquímica

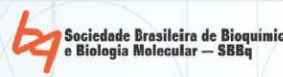

V. 20, N.1 / 2020

Submitted in: 4 jun 2020 Published in: 10 ago 2020

ISSN: 2318-8790

ISSN (until 2012): 1677-2318

Federal de Viçosa; 2006.

[25] Freitas, E. Tempestade de ideias no ensino (brainstorming). Brasil escola. [acesso em 06 set 2019]. Disponível em: https://educador.brasilescola.uol.com.br/orientacoes/tempestadeideias-no-ensino-brainstorming.htm

[26] Ruppenthal, R, Santos, TL, Prati, TV. A utilização de mídias e TICs nas aulas de biologia: como explorá-las. Cadernos do aplicação. UFRGS [periódicos na internet]. 2011. [acesso em 15 de abril de 2019]. Disponível https://seer.ufrgs.br/CadernosdoAplicacao/article/view/18163/23015

[27] Antunes, $\mathrm{CH}$, Pileggi, M, Pazda, AK. Por que a visão científica da microbiologia não tem o mesmo foco na percepção da microbiologia no ensino médio? In: Anais do III Simpósio nacional de ensino de ciência e tecnologia.; 26 a 28 de setembro de 2012., Ponta Grossa-PR. [s.n.].

[28] Lima, DB, Garcia, RN. Uma investigação sobre a importância das aulas práticas de biologia no ensino médio. Cadernos do aplicação. UFRGS [periódicos na internet]. 2011. [acesso em 17 de abril de 2019]. Disponível em: https://seer.ufrgs.br/CadernosdoAplicacao/article/view/22262

[29] Radetzke, FS. O ensinar e o aprender por meio de projetos: cooperação e cidadania. Revista Insignare Scientia 2019; 2(3): 142-153.

[30] Alves, SBF, Caldeira, AMA. Biologia e ética: um estudo sobre a compreensão e atitudes de alunos do ensino médio frente ao tema genoma/dna. Ensaio Pesquisa em Educação em Ciências 2005; 7(1): 12-23.

https://doi.org/10.1590/1983-21172005070103

[31] Krasilchik, M. Prática de ensino de Biologia. 4. ed. São Paulo: EDUSP; 2008.

[32] Lousan, NEP. Os desafios do professor de biologia na promoção de saúde na escola pública: metodologias ativas de aprendizagem como caminho para a superação. Sorocaba. Dissertação de mestrado [Educação nas Profissões da Saúde] -Pontifícia Universidade Católica de São Paulo, 2015.

[33] Carvalho, AMP (org.), De Oliveira, CMA, Scarpa, DL, Sasseron, LH, Sedano, L, Silva, MB, et al. Ensino de ciências por investigação: condições para implementação em sala de aula. São Paulo: Editora Cengage Learning; 2013.

[34] Libâneo, JC. Educação \& realidade. [periódicos na internet]. 2015. [acesso em 18 mai 2019]. Disponível em: http://dx.doi.org/10.1590/2175-623646132

[35] Cunha, MB. Jogos no ensino de química: considerações teóricas para sua utilização em sala de aula. Química Nova na Escola 2012; 34(2): 92-98.

[36] Morin, E. Os sete saberes necessários à educação do futuro. 4. ed. São Paulo: Cortez; 2002.

[37] Mendes, AM, Leitão, AC. Elie Metchnikoff na Ilha da Madeira. Rev. Portuguesa de Ciências Veterinárias 2008; Suplemento 103 (567-568) 241-244. 


\section{Journal of Biochemistry Education}

[38] Kutschera, U, Niklas, KJ. Julius Sachs (1868): The father of plant physiology. American Journal of Botany 2018; 105(4): 656-666. doi:10.1002/ajb2.1078

\section{Agradecimentos}

À Coordenação de Aperfeiçoamento de Pessoal de Nível Superior - CAPES, pelo suporte financeiro, na forma de bolsa de mestrado no ProBio/UECE.

\section{Materiais adicionais}

https://drive.google.com/file/d/16PK8ksZJAAkfwyGq1zkF6kmg1-jnA1vY/view?usp=sharing

\begin{tabular}{|c|l|c|}
\hline Material & \multicolumn{1}{|c|}{ Descrição } & Tipo de arquivo \\
\hline Apêndice A & Plano de aulas práticas & Texto - Word \\
\hline Apêndice B & Materiais e procedimentos & Texto - Word \\
\hline Apêndice C & Questionário aplicado aos alunos & Texto - Word \\
\hline Apêndice D & Roteiro da atividade prática sobre fermentação & Texto - Word \\
\hline Apêndice E & Roteiro da atividade prática sobre fotossíntese & Texto - Word \\
\hline Apêndice F & $\begin{array}{l}\text { Roteiro da atividade prática sobre respiração } \\
\text { celular }\end{array}$ & Texto - Word \\
\hline Fotos & Experimentos sobre a fermentação e a fotossíntese & Fotos - jpg \\
\hline
\end{tabular}

